\title{
Equilibrium Phase Diagram of Mg-Ti-O System (High Titanium Oxide Part) III*
}

Tetsuro Yoshida and Takeshi TAKEI**

\begin{abstract}
In the previous paper, the authors noted the existence of the eutectics $\alpha\left(\mathrm{TiO}_{2}\right.$ solid solution $)+\beta$ ( $\mathrm{Ti}_{3} \mathrm{O}_{5}$ solid solution) phases and $\beta+\gamma\left(\mathrm{Ti}_{2} \mathrm{O}_{3}\right.$ solid solution) in the system $\mathrm{TiO}_{2}-\mathrm{Ti}_{2} \mathrm{O}_{3}$. It was also found that the $\varepsilon$ phase $\left(\mathrm{MgO} .2 \mathrm{TiO}_{2}\right.$ solid solution) dissolves large amount of $\beta$ phase and the domain of this phase seemes to extend to the point (composition) at which the atomic ratio of $\mathrm{Ti} / \mathrm{Mg}$ is nearly 10 , and the $\varepsilon$ phase makes eutectic with the $\beta$ phase.

In this paper, phase relations of these phases in the ternary system $\mathrm{TiO}_{2}-\mathrm{Ti}_{2} \mathrm{O}_{3}-\mathrm{MgO}$ (a part of $\mathrm{Mg}-$ Ti-O system) estimated by further experiments are described.
\end{abstract}

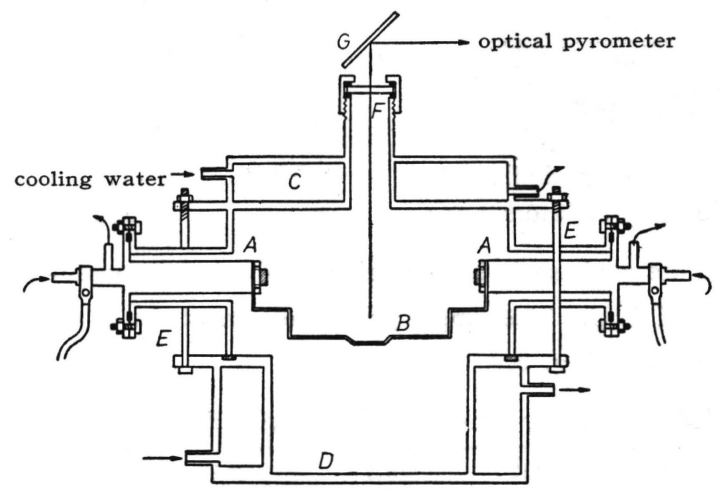

Fig. 1 Schematic representation of apparatus for melting point measurement.

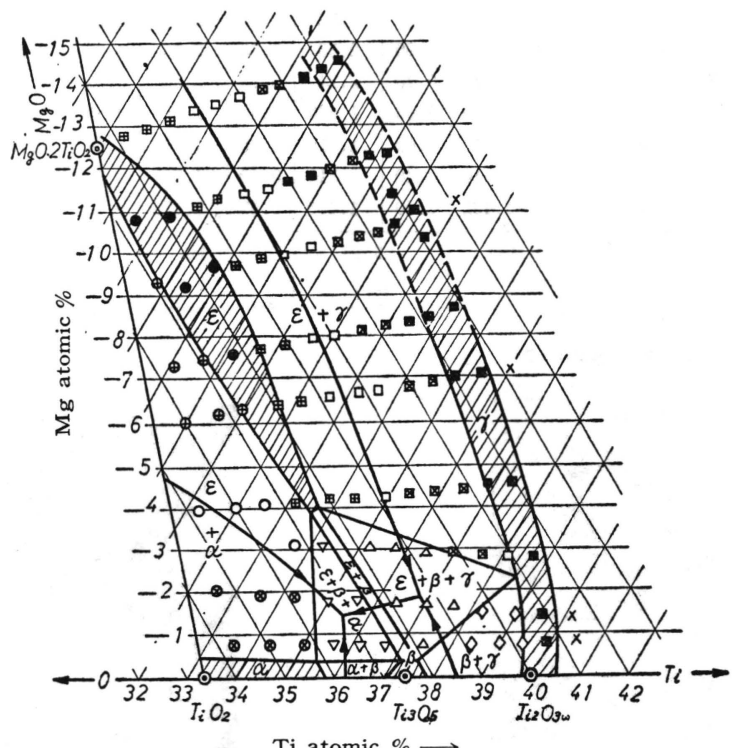

Fig. 2 Phase boundary diagram of $\mathrm{Mg}$-Ti-O system (high titanium oxide part).

* Studies on High Titania Slag. (Part 5)

** Fujihara Memorial Faculty of Engineering, Keio University, Koganei

The original written in Japanese can be seen in J. Electrochem. Soc. Japan, 28, 16 (1960) 
Samples were prepared by arc melting of mixtures of chemically pure oxides and sponge titanium with tungsten electrode in argon gas by the apparatus shown in the previous paper. Microscopic observation, x-ray and chemical analysis were carried out for these samples.

The melting points of these samples were also measured by the apparatus shown in Fig. 1, in which samples were heated on molybdenum foil in vacuum or argon gas.

\section{A. Domain of $\boldsymbol{r}$ solid solution.}

1. Samples marked by in Fig. 2 are consisted of the $r$ single phase. Photo 1 and 2 are their microphotographs. The $r$ phase is reddish purple and brittle, being hardly etched by HF solution.

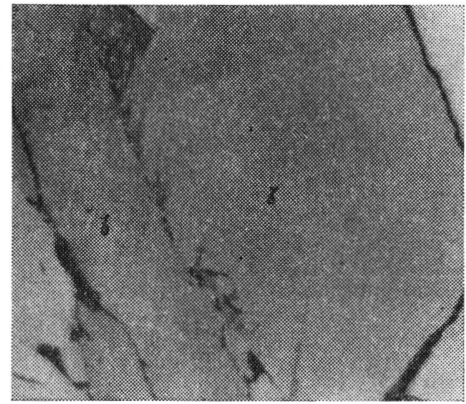

Photo. 1 Microphotograph of $r$ single phase sample (Mg 7.2 atomic \%)

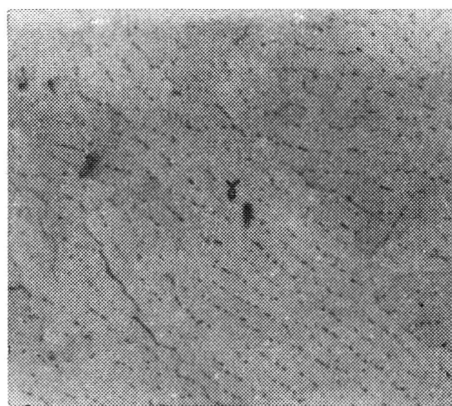

Photo. 2 Microphotograph of $r$ single phase sample (Mg 14.5 atomic \%)

2. The crystal lattice of the $r$ phase is hexagonal, and the lattice parameters $a_{0}$ and $c_{0}$ change nearly linearly with atomic ratio of $\mathrm{Ti} / \mathrm{Mg}$. The single phase domain of the $r$ phase seemes to extend towards $\mathrm{MgTiO}_{3}$ as shown in Table 1 and Fig. 6 .

Table 1 X-ay Analysis of $r$ Single Phase Samples

\begin{tabular}{|c|c|c|c|c|c|c|c|c|c|c|c|c|c|c|c|c|}
\hline \multirow{2}{*}{$\begin{array}{l}\mathrm{Mg} / \mathrm{Ti} \\
\text { Atomic ratio } \\
\text { Miller index }\end{array}$} & \multicolumn{2}{|c|}{0} & \multicolumn{2}{|c|}{0.04} & \multicolumn{2}{|c|}{0.12} & \multicolumn{2}{|c|}{0.18} & \multicolumn{2}{|c|}{0.29} & \multicolumn{2}{|c|}{0.33} & \multicolumn{2}{|c|}{0.40} & \multicolumn{2}{|c|}{0.51} \\
\hline & $I / I_{1}$ & $d(\AA)$ & $I / I_{1}$ & $d(\AA)$ & $I / I_{1}$ & $d(\AA)$ & $I / I_{1}$ & $d(\AA)$ & $I / I_{1}$ & $d(\AA)$ & $I / I_{1}$ & $d(\AA)$ & $I / I_{1}$ & $d(\AA)$ & $I / I_{1}$ & $d(\AA)$ \\
\hline (102) & 1.00 & 3.74 & 1.00 & 3.74 & 1.00 & 3.74 & 1.00 & 3.74 & 0.90 & 3.74 & 0.75 & 3.74 & 0.65 & 3.74 & 0.55 & 3.72 \\
\hline (014) & 0.55 & 2.71 & 0.75 & 2.71 & 0.85 & 2.72 & 0.95 & 2.72 & 1.00 & 2.72 & 0.90 & 2.72 & 1.00 & 2.72 & 1.00 & 2.72 \\
\hline (110) & 0.55 & 2.59 & 0.65 & 2.57 & 0.70 & 2.57 & 0.90 & 2.56 & 0.70 & 2.56 & 0.80 & 2.56 & 0.70 & 2.56 & 0.55 & 2.54 \\
\hline (113) & 0.30 & 2.24 & 0.45 & 2.24 & 0.45 & 2.24 & 0.70 & 2.24 & 0.65 & 2.24 & 0.55 & 2.23 & 0.55 & 2.23 & 0.40 & 2.23 \\
\hline (204) & 0.50 & 1.870 & 0.65 & 1.866 & 0.55 & 1.866 & 0.55 & 1.866 & 0.60 & 1.863 & 0.55 & 1.863 & 0.55 & 1.863 & 0.30 & 1.859 \\
\hline (116) & 0.55 & 1.707 & 0.80 & 1.707 & 0.80 & 1.710 & 1.00 & 1.710 & 0.95 & 1.710 & 1.00 & 1.710 & 0.75 & 1.710 & 0.60 & 1.710 \\
\hline (124) & 0.25 & 1.514 & 0.20 & 1.512 & 0.35 & 1.510 & 0.40 & 1.510 & 0.40 & 1.508 & 0.40 & 1.506 & 0.35 & 1.503 & 0.20 & 1.501 \\
\hline$(300)$ & 0.25 & 1.488 & 0.35 & 1.484 & 0.45 & 1.482 & 0.40 & 1.480 & 0.45 & 1.478 & 0.45 & 1.475 & 0.45 & 1.473 & 0.02 & 1.471 \\
\hline$a_{0}$ & \multirow{2}{*}{\multicolumn{2}{|c|}{$\begin{array}{l}5.15 \\
13.7\end{array}$}} & \multirow{2}{*}{\multicolumn{2}{|c|}{$\begin{array}{c}5.14 \\
13.8\end{array}$}} & \multirow{2}{*}{\multicolumn{2}{|c|}{$\begin{array}{r}5.13 \\
13.8\end{array}$}} & \multirow{2}{*}{\multicolumn{2}{|c|}{$\begin{array}{r}5.13 \\
13.8\end{array}$}} & \multirow{2}{*}{\multicolumn{2}{|c|}{$\begin{array}{r}5.12 \\
13.8\end{array}$}} & \multirow{2}{*}{\multicolumn{2}{|c|}{$\begin{array}{c}5.11 \\
13.8\end{array}$}} & \multirow{2}{*}{\multicolumn{2}{|c|}{$\begin{array}{r}5.10 \\
13.8\end{array}$}} & \multirow{2}{*}{\multicolumn{2}{|c|}{$\begin{array}{r}5.10 \\
13.8\end{array}$}} \\
\hline$c_{0}$ & & & & & & & & & & & & & & & & \\
\hline
\end{tabular}

\section{B. Domains consisting of two phases.}

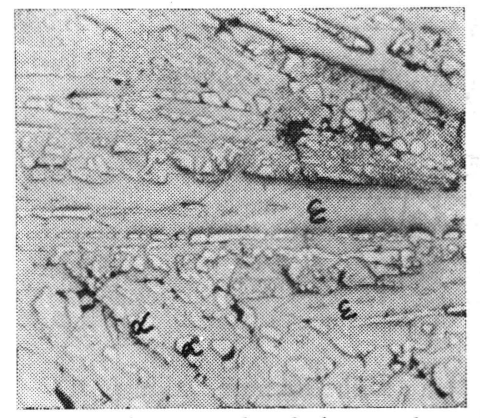

Photo. 3 Microphotograph of the samlpe marked by $\oplus$ in Fig. 2 ; primary crystal $\varepsilon$, and eutectic $\varepsilon+\alpha$ phase.

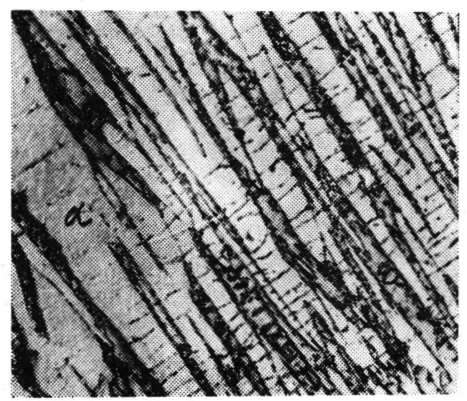

Photo. 4 Microphotograph of the sample marked by $\otimes$ in Fig. 2; primary crystal $\alpha$, and eutectic $\alpha+\varepsilon$. 


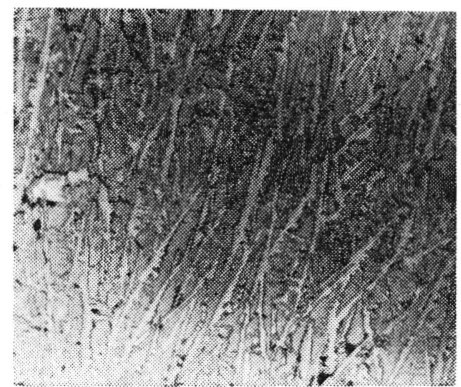

Photo. 5 Microphotograph of the sample marked by $\bigcirc$ in Fig. $2 ; \varepsilon+\alpha$ eutectic mixture.

1. Samples marked by $\oplus, \bigcirc$ and $\otimes$ in Fig. 2 consist of $\alpha+\varepsilon$ two phases. Photo 3 is an example of the microphotograph of the sample marked by $\oplus$, in which $\varepsilon$ primary crystal and $\varepsilon+\alpha$ eutectic are observable. In Photo. $4, \alpha$ phase (bright) is primary crystal and in Photo 5 both crystals seem to be precipitated simultaneously.

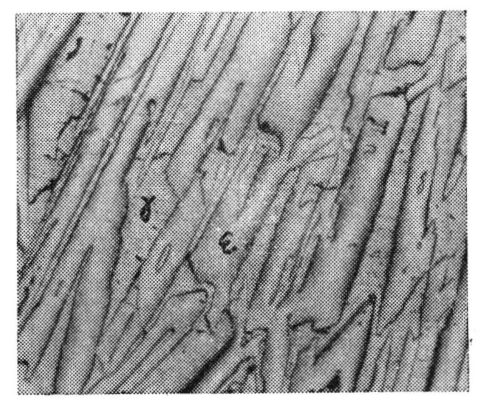

Photo. 6 Microphotograph of the sample marked by $\boxplus$ in Fig. 2; primary crystal $\varepsilon$, and eutectic $\varepsilon+\gamma$.

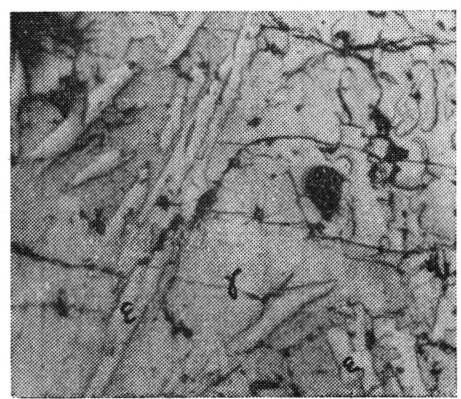

Photo. 7 Microphotograph of the sample marked by $\otimes$ in Fig. 2; primary crystal $r$, and eutectic $r+\varepsilon$.

2. Samples $\boxplus, \square$ and $\bigotimes$ in Fig. 2 consists of $\varepsilon+r$ two phases and from this observation the domain of $\varepsilon+r$ phase is estimated. In Photo. 6 the $\varepsilon$ phase is primary crystal, while in Photo 7 the $r$ phase is primary. $\varepsilon$ and $r$ phases crystallise by eutectic reaction.

3. As reported in the previous paper, three eutectics $\alpha+\beta, \beta+\gamma$ and $\varepsilon+\beta$ are observable and their domains are shown in Fig. 2.

\section{Domain consisting of three phases.}

1. Samples $\nabla$ in Fig. 2 consists of $\alpha+\beta+\varepsilon$ three phases. As shown in Photo 8 the $\alpha$ phase is bright, the $\beta$ phase is golden yellow and the $\varepsilon$ phase is grayish blue. The $\beta$ phase is bright even

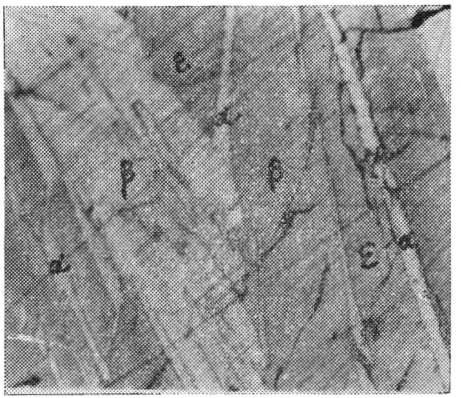

Photo. 8 Microphotograph of the sample marked by $\nabla$ in Fig $2 ; \alpha+\beta+\varepsilon$ phases.

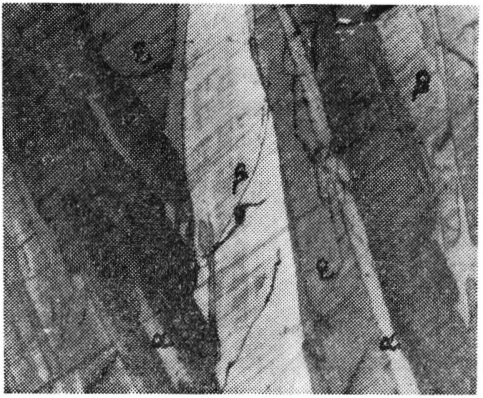

Photo. 9 Microphotograph of the same sample in Photo. 8 under polarized light. 


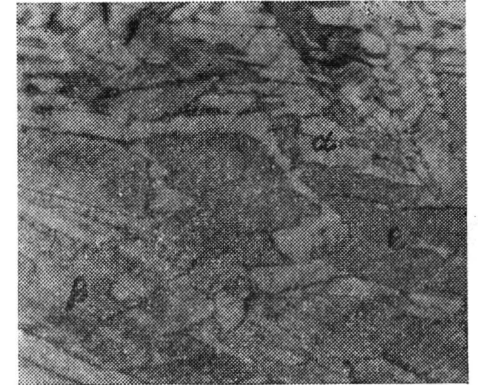

Photo. 10 Microphotograph of the $\alpha+\beta+\varepsilon$ phase sample. The parallel cleavage is observable in $\beta$ phase when etched by HF solution.

Table 2 Melting Point of the Samples in $\mathrm{Mg}-\mathrm{Ti}-\mathrm{O}$ System.

\begin{tabular}{|c|c|c|c|c|}
\hline \multicolumn{3}{|c|}{ Composition atomic $\%$} & \multirow{2}{*}{$\begin{array}{l}\text { Melting } \\
\text { point }{ }^{\circ} \mathrm{C}\end{array}$} & \multirow{2}{*}{$\begin{array}{l}\text { Cystalline } \\
\text { phase }\end{array}$} \\
\hline $\mathrm{Mg}$ & $\mathrm{Ti}$ & $\mathrm{O}$ & & \\
\hline - & 34.8 & 65.2 & 1730 & $\alpha$ \\
\hline- & 35.5 & 64.5 & 1680 & $\alpha$ \\
\hline- & 36.2 & 63.8 & 1610 & $\alpha+\beta$ \\
\hline - & 36.8 & 63.2 & 1650 & $\alpha+\beta$ \\
\hline- & 37.6 & 62.4 & 1690 & $\beta$ \\
\hline - & 38.2 & 61.8 & 1640 & $\beta+\gamma$ \\
\hline- & 38.8 & 61.2 & 1680 & $\beta+\gamma$ \\
\hline- & 39.5 & 60.5 & 1750 & $\beta+\gamma$ \\
\hline- & 40.0 & 60.0 & 1820 & $r$ \\
\hline 0.6 & 37.1 & 62.3 & 1680 & $\beta+\varepsilon$ \\
\hline 2.3 & 35.2 & 62.5 & 1600 & $\beta+\varepsilon$ \\
\hline 7.0 & 31.5 & 62.5 & 1620 & $\varepsilon$ \\
\hline 9.2 & 28.4 & 62.4 & 1630 & $\varepsilon$ \\
\hline 10.7 & 26.8 & 62.5 & 1640 & $\varepsilon$ \\
\hline 10.9 & 27.2 & 61.9 & 1640 & $\varepsilon$ \\
\hline 11.1 & 27.6 & 61.3 & 1620 & $\varepsilon+\tau$ \\
\hline 11.4 & 28.5 & 60.2 & 1610 & $\varepsilon+r$ \\
\hline 11.7 & 29.2 & 59.1 & 1610 & $\varepsilon+r$ \\
\hline 12.0 & 30.0 & 58.0 & 1620 & $\varepsilon+r$ \\
\hline 12.4 & 31.0 & 56.6 & 1620 & $r$ \\
\hline 7.4 & 29.7 & 62.9 & 1630 & $\alpha+\varepsilon$ \\
\hline 7.7 & 30.6 & 61.7 & 1630 & $\varepsilon+\gamma$ \\
\hline 7.9 & 31.6 & 60.5 & 1600 & $\varepsilon+\gamma$ \\
\hline 8.1 & 32.5 & 59.4 & 1610 & $\varepsilon+\gamma$ \\
\hline 8.3 & 33.4 & 58.3 & 1620 & $\varepsilon+r$ \\
\hline 8.6 & 34.2 & 57.3 & 1620 & $r$ \\
\hline 3.9 & 31.4 & 64.7 & 1600 & $\alpha+\varepsilon$ \\
\hline 4.0 & 32.1 & 63.9 & 1600 & $\alpha+\varepsilon$ \\
\hline 4.1 & 32.5 & 63.4 & 1610 & $\alpha+\varepsilon$ \\
\hline 4.2 & 33.7 & 62.1 & 1610 & $\varepsilon+r$ \\
\hline 4.3 & 34.9 & 60.8 & 1590 & $\varepsilon+\gamma$ \\
\hline 4.4 & 35.8 & 59.8 & 1610 & $\varepsilon+\gamma$ \\
\hline 4.6 & 36.8 & 58.6 & 1620 & $r$ \\
\hline 0.5 & 33.7 & 65.8 & 1700 & $\alpha+\varepsilon$ \\
\hline 0.8 & 34.9 & 64.3 & 1650 & $\alpha+\varepsilon$ \\
\hline 0.8 & 36.3 & 62.9 & 1600 & $\alpha+\varepsilon+\beta$ \\
\hline 0.9 & 37.5 & 61.6 & 1610 & $\beta+\varepsilon+\gamma$ \\
\hline 0.9 & 38.7 & 60.4 & 1640 & $\beta+\gamma$ \\
\hline $0: 9$ & 40.0 & 59.1 & 1710 & $r$ \\
\hline 1.9 & 32.8 & 65.3 & 1650 & $\alpha+\varepsilon$ \\
\hline 1.6 & 38.7 & 59.7 & 1650 & $\beta+\gamma$ \\
\hline 9.9 & 30.1 & 60.0 & 1600 & $\varepsilon+\gamma$ \\
\hline
\end{tabular}

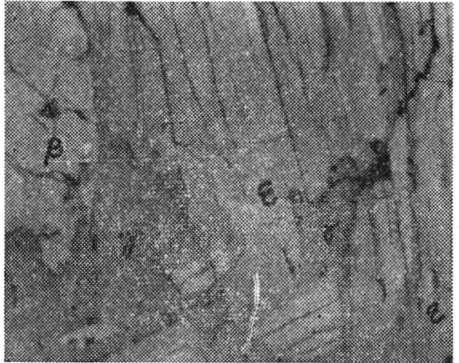

Photo. 11 Microphotograph of the sample marked by $\triangle$ in Fig. $2 ; \beta+\gamma+\varepsilon$ phases.

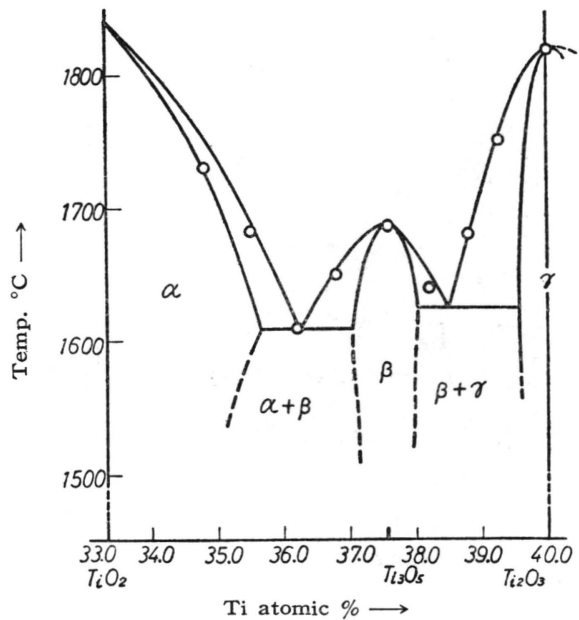

Fig. 3 Phase diagram of $\mathrm{TiO}_{2}-\mathrm{Ti}_{2} \mathrm{O}_{3}$ system.

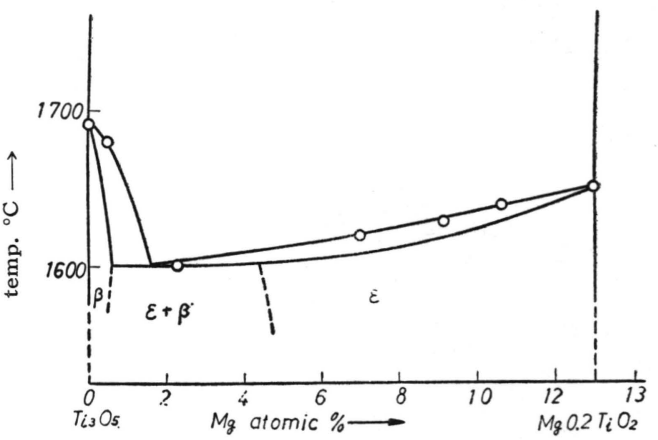

Fig. 4 Phase diagram of $\mathrm{MgO} \cdot 2 \mathrm{TiO}_{2}-\mathrm{Ti}_{3} \mathrm{O}_{5}$ system. 


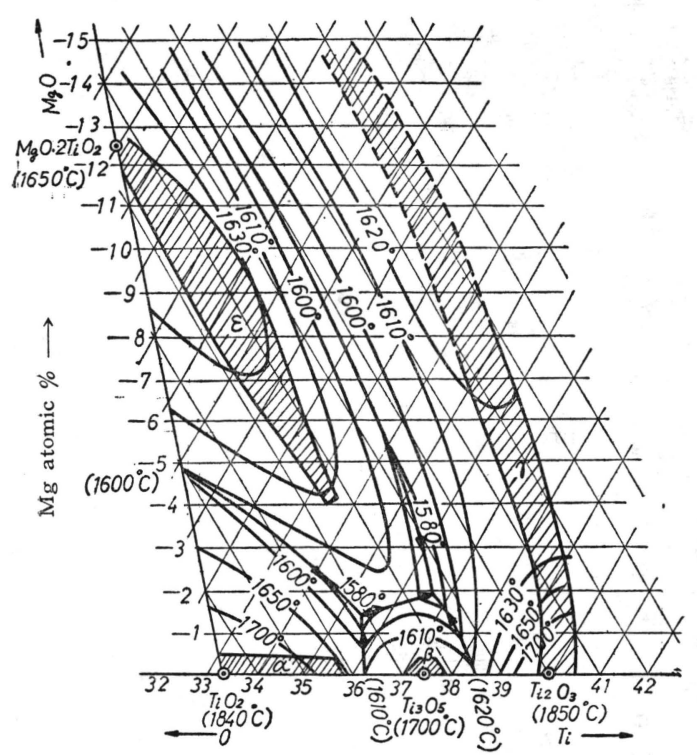

Ti atomic $\% \longrightarrow$

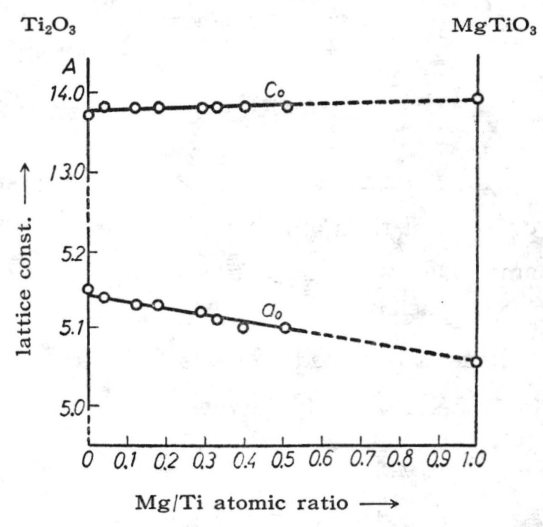

Fig. 6 Relation between $\mathrm{Mg} / \mathrm{Ti}$ atomic ratio and lattice constant of $r$ single phase samples.

Fig. 5 Phase diagram of $\mathrm{Mg}-\mathrm{Ti}-\mathrm{O}$ system. (high titanium oxide part) (liquidus surface)

under the cross-polarized light as shown in Photo 9. In Photo. 10 characteristic parallel cleavage lines in the $\beta$ phase, which is produced by deep etching with HF solution, are shown.

2. Samples $\nabla$ in Fig. 2 consist of $\beta+r+\varepsilon$ three phases, and the domain of these three phases are estimated roughly from the observations. Photo 11 is a microphotograph of this three-phases sample. The $r$ phase is easily identified by its reddish purple color.

\section{Liquidus surface.}

1. Melting points and phases observed are listed in Table 2.

2. Fig. 3 is the equilibrium phase diagram of the $\mathrm{TiO}_{2}-\mathrm{Ti}_{2} \mathrm{O}_{3}$ system supposed from the above mentioned observations. The melting point of $\mathrm{Ti}_{3} \mathrm{O}_{5}$ is $1690^{\circ} \mathrm{C}$, and that of $\mathrm{Ti}_{2} \mathrm{O}_{3}$ is about $1820^{\circ} \mathrm{C}$. The eutectic composition of $\alpha+\beta$ eutectic is $\mathrm{Ti} 36.2, \mathrm{O} 63.8$ at. $\%$, and that of $\beta+\gamma$ eutectic is $\mathrm{Ti} 38.5$, $\mathrm{O} 61.5 \mathrm{~atm}$. \%. The eufectic temperature of the former is estimated to be $1610^{\circ} \mathrm{C}$, while that of the latter is $1620^{\circ} \mathrm{C}$.

3. Fig. 4 is the equilibrium phase diagram of the $\mathrm{MgO} 2 \mathrm{TiO}_{2}-\mathrm{Ti}_{3} \mathrm{O}_{5}$ system. The eutectic composition of $\varepsilon$ and $\beta$ phases is $\mathrm{Mg} 1.5, \mathrm{Ti} 36.0, \mathrm{O} 62.5 \mathrm{~atm} . \%$, and the eutectic temperature is about $1600^{\circ} \mathrm{C}$.

4. The liquidus surface of the ternary system is shown by isothermal lines in Fig. 5. Estimated binary eutectic lines $\alpha+\beta, \alpha+\varepsilon, \beta+\varepsilon \varepsilon+\gamma$ and $\beta+\gamma$ phases are shown also in the figure.

5. The composition of $\alpha+\beta+\varepsilon$ ternary eutectic is about $\mathrm{Mg} 1.5, \mathrm{Ti} 35.5, \mathrm{O} 63.0 \mathrm{~atm}$. \%, and that of $\beta+\gamma+\varepsilon$ ternary eutectic is about $\mathrm{Mg} 2.0$, Ti 37.0, $\mathrm{O} 61.0$ at. $\%$. The eutectic temperature of the former is estimated to be about $1570^{\circ} \mathrm{C}$, and that of the latter $1550^{\circ} \mathrm{C}$.

(Received November 4, 1959) 